\title{
A Virion Concentration Method for Detection of Human Enteric Viruses in Oysters by PCR and Oligoprobe Hybridization
}

\author{
LEE-ANN JAYKUS, * RICARDO DE LEON, $\dagger$ AND MARK D. SOBSEY \\ Department of Environmental Sciences and Engineering, University of North Carolina at \\ Chapel Hill, Chapel Hill, North Carolina 27599-7400
}

Received 7 June 1995/Accepted 13 March 1996

\begin{abstract}
This article reports the development of a method to purify and concentrate intact virions from oyster extracts to a volume and quality compatible with viral genomic nucleic acid amplification by reverse transcriptase PCR (RT-PCR) and confirmation by oligonucleotide probe hybridization. Fifty-gram oyster samples were processed by an adsorption-elution-precipitation method and then seeded with $10^{1}$ to $10^{5}$ PFU of poliovirus type 1 (PV1) or hepatitis A virus (HAV). Seeded viruses in oyster extracts were purified by fluorocarbon extraction and concentrated by polyethylene glycol (PEG) precipitation and elution. Virus recovery after elution of PEG precipitates was dependent upon PEG concentration and averaged $60 \%$ for PV1 and $40 \%$ for HAV. The next processing step used the protein-precipitating agent Pro-Cipitate (Affinity Technology, Inc., Brunswick, N.J.) in an adsorption-elution-precipitation scheme to further concentrate viruses and reduce sample volumes to 100 $\mu l$. Oyster extracts processed by Pro-Cipitate adsorption-elution-precipitation were directly compatible with RT-PCR and yielded virus recoveries of $>\mathbf{8 0} \%$ for both PV1 and HAV. When extracts from 50-g oyster samples were seeded and processed by the combined concentration and purification scheme, direct RT-PCR detection of viral genomic RNA was possible at initial inoculum levels of 10 PFU for both PV1 and HAV and with low levels of Norwalk virus. Virus recoveries based on cell culture infectivity were 25 to $35 \%$ for PV1 and 5 to $10 \%$ for HAV. When tested on artificially contaminated raw oysters, the combined method successfully detected $\geq 10^{3}$ PFU of PV1 and HAV and $10^{5}$ RT-PCR-amplifiable units of Norwalk virus. Virus detection by RT-PCR and cell culture infectivity was consistent and well correlated among replicate samples and at different virus titers. The procedure developed in this study is rapid, sensitive, and effective for the direct detection of enteric viruses in oysters by RT-PCR.
\end{abstract}

Enteric virus transmission due to the consumption of fecally contaminated shellfish is a significant public health concern $(20,25)$. While the fecal coliform group of bacteria are universally accepted as the criterion for the sanitary quality of shellfish and their harvesting waters, the scientific consensus is that these indicators do not reflect the occurrence of enteric viruses in the marine environment (9). In the absence of effective indicator systems, investigators have attempted the direct detection of viruses from shellfish and their harvesting waters. These techniques have relied on cumbersome methods of virus extraction and subsequent detection based on virus infectivity for susceptible, live laboratory hosts (25). These virus concentration and detection steps are expensive, timeconsuming, technically difficult, and lacking in sensitivity. They are further limited by the need for large sample sizes to detect the low virus levels that still pose a health risk and the lack of susceptible hosts for the more epidemiologically important viruses, such as hepatitis A virus (HAV) and the Norwalk-type viruses $(14,25)$.

Reverse transcriptase (RT) PCR is a rapid, economical, sensitive, and specific approach which has been used recently for the amplification of nucleic acid sequences for the enteroviruses $(2,12,21)$, HAV (13), rotaviruses (10), and Norwalk virus (6) in clinical fecal specimens for which expected viral contamination levels are high. However, there is a need to

\footnotetext{
* Corresponding author. Present address: Department of Food Science, North Carolina State University, Box 7624, Raleigh, NC 276957624. Phone: (919) 515-2971. Fax: (919) 515-7124. Electronic mail address: leeann_Jaykus@ncsu.edu.

$\dagger$ Present address: Metropolitan Water District of Southern California, La Verne, CA 91750.
}

develop methodology designed specifically to detect the lower levels of viral contamination typically expected in shellfish samples.

Most applications of RT-PCR to the detection of viruses in environmental samples have involved the extraction of total sample RNA followed by RT-PCR amplification of viral nucleic acid sequences $(1,16)$. Destruction of the integrity of the virions during this processing exposes naked viral RNA to potential degradation and, by destroying infectivity, precludes a systematic comparison of virus detection by both RT-PCR and cell culture infectivity. Remaining RT-PCR inhibitors have necessitated further nucleic acid purification steps and/or double PCR $(11,16)$.

An alternative approach would be the direct isolation and purification of intact virions from shellfish extracts prior to application of nucleic acid amplification methods. The goal of this research was to develop procedures to purify and concentrate intact virions from shellfish extracts to a volume and quality compatible with direct RT-PCR amplification of viral genomic nucleic acid sequences and subsequent confirmation of amplicon identity by oligonucleotide probe (oligoprobe) hybridization.

\section{MATERIALS AND METHODS}

Viruses and cells. Poliovirus type 1 (PV1), strain LSc, was propagated in BGMK (African green monkey kidney-derived) cells and assayed for infectivity by the plaque technique (26). HAV, cytopathic strain HM-175, was grown and plaque assayed in FRhK-4 (fetal rhesus monkey kidney-derived) cells (3). Viruses in infected cell lysates were purified after one rapid freeze-thaw followed by extraction with an equal volume of trichlorotrifluoroethane (Freon) as described previously (26).

Norwalk virus was obtained as stool samples from human volunteers experimentally infected with the 8FIIa prototype strain of Norwalk inoculum (a gift of G. Richards, National Marine Fisheries Service, Charleston, S.C.). Ten or 20\% 
stool suspensions in phosphate-buffered saline (PBS) were fluorocarbon extracted and centrifuged at $1,500 \times g$. The resulting supernatants were used directly as inocula in experiments.

Shellfish sample processing for RT-PCR. Fifty-gram samples of Eastern oysters (Crassostrea virginica) obtained from local commercial sources were processed by the adsorption-elution-precipitation scheme of Sobsey et al. (26). Previous studies have shown that poliovirus and HAV are recovered efficiently from oysters by this method $(15,26)$. Final sample volumes of approximately 15 $\mathrm{ml}$ were seeded with PV1 or HAV and further processed for virus concentration and purification.

RT-PCR inhibitors were initially removed by two consecutive extractions with equal volumes of Freon. After centrifugation at $12,000 \times g$ and $5^{\circ} \mathrm{C}$ for $20 \mathrm{~min}$, the resulting supernatant was adjusted to $\mathrm{pH} 7.3$ to 7.4 and $0.3 \mathrm{M} \mathrm{NaCl}$, supplemented with 4 to $12 \%$ polyethylene glycol (PEG) 6000 , and incubated overnight at $4^{\circ} \mathrm{C}$ to precipitate viruses. The precipitated viruses were recovered by centrifugation at $6,000 \times g$ and $4^{\circ} \mathrm{C}$ for $20 \mathrm{~min}$ and resuspended in one-seventh the original sample volume with $50 \mathrm{mM}$ Tris- $-2.2 \%$ Tween 20 (pH 9.0). Resuspended precipitates were held at room temperature for $30 \mathrm{~min}$ to aid virus elution and then centrifuged for $15 \mathrm{~min}$ at $8,200 \times g$ and room temperature to remove extraneous particulates. The resulting supernatant with a volume of 1.5 to $2.0 \mathrm{ml}$ was a 10 -fold concentrate of the initial extract volume.

Viruses in 1-ml volumes of the PEG eluants were precipitated for $15 \mathrm{~min}$ by the addition of an equal volume of Pro-Cipitate (Affinity Technology, Inc., New Brunswick, N.J.). The solid phase was recovered by centrifugation for $15 \mathrm{~min}$ at room temperature and $13,800 \times g$. To elute adsorbed viruses, $4 \mathrm{ml}$ of $50 \mathrm{mM}$ Tris- $0.2 \%$ Tween 20 (pH 9.0) was added, and the sample was gently rotated for $1 \mathrm{~h}$ at room temperature and then centrifuged at $6,000 \times g$ and $15^{\circ} \mathrm{C}$ for $20 \mathrm{~min}$ to remove excess Pro-Cipitate. Viruses in the eluant were further concentrated by a secondary PEG precipitation with 5 to $10 \%$ PEG and $0.3 \mathrm{M} \mathrm{NaCl}$. After 2 $\mathrm{h}$ at $4^{\circ} \mathrm{C}$ and gentle rotation, the solutions were centrifuged at $6,000 \times g$ and $4^{\circ} \mathrm{C}$ for $20 \mathrm{~min}$. The virus-containing precipitate was resuspended in one-seventh the original volume with $50 \mathrm{mM}$ Tris- $0.2 \%$ Tween 20 (pH 8.0). Ten-microliter aliquots of final concentrates, representing 5 to $10 \%$ of the total sample volume, were used in RT-PCRs. The entire sample concentration protocol is outlined in Fig. 1

PCR primers and oligoprobes. The oligonucleotide primer and probe sequences for enteroviruses and HAV used in this study have been described previously $(7,23)$. The highly conserved $5^{\prime}$ untranslated region of the enteroviruses was used as the target for the synthesis of a 197-bp pan-enterovirus cDNA (5' primer, CCTCCGGCCCCTGAATG; 3' primer, ACCGGATGGCCAATC CAA; internal oligoprobe, TACTTTGGGTGTCCGTGTTTC). For HAV, the genomic region corresponding to the VP1 to VP3 capsid protein-interphase was the target for the 192-bp cDNA (5' primer, CAGCACATCAGAAAGGTGAG; $3^{\prime}$ primer, CTCCAGAATCATCTCCAAC; internal oligoprobe, TGCTCCTC TTTATCATGCTATG). For Norwalk virus, the genomic region encoding the viral polymerase was the target for a $260-\mathrm{bp}$ cDNA (5) (5' primer, CAAATTAT GACAGAATCCTTC; 3' primer, GAGAAATATGACATGGATTGC; internal oligoprobe, ATGTCATCAGGGTCAAAGAGG). The downstream or antisense $3^{\prime}$ primers are complementary to the plus-sense virion RNA, and the upstream $5^{\prime}$ primers are homologous to the plus-sense viral RNA. Internal oligomer probes were synthesized in the plus-sense orientation so that they hybridize only with cDNA or PCR products and not with viral genomic plus-sense RNA.

RT-PCR. RT-PCRs were done with the Gene-Amp kit (Perkin-Elmer Cetus Corp., Norwalk, Conn.) as described in the manufacturer's instructions except that reaction volumes for reverse transcription were increased from 20 to $30 \mu \mathrm{l}$ to accommodate a $10-\mu \mathrm{l}$ sample. Virion RNA was released by heating of reaction mixtures at $99^{\circ} \mathrm{C}$ for $5 \mathrm{~min}$, followed by the addition of RT $(2.5 \mathrm{U})$ and RNase inhibitor $(1.0 \mathrm{U})$. Reverse transcription was done at $42^{\circ} \mathrm{C}$ for $1 \mathrm{~h}$ with random primers, and then the tubes were heated to $99^{\circ} \mathrm{C}$ for $5 \mathrm{~min}$ to inactivate the enzyme. After chilling on ice, the tubes were supplemented with $5 \mathrm{U}$ of $\mathrm{Taq}$ polymerase and primer pairs as appropriate. PCR amplification was performed for 40 cycles, each consisting of $95^{\circ} \mathrm{C}$ for $1.5 \mathrm{~min}, 55^{\circ} \mathrm{C}$ for $1.5 \mathrm{~min}$, and $72^{\circ} \mathrm{C}$ for $1.5 \mathrm{~min}$. A 10 - to $15-\mu \mathrm{l}$ portion of RT-PCR product, which represented 10 to $15 \%$ of the total reaction volume, was analyzed by gel electrophoresis on $2 \%$ agarose, stained with ethidium bromide, and visualized by UV light. In some experiments, the inhibitory effect of oyster extracts was evaluated by serial dilution of concentrated oyster samples and addition of a constant amount of virus prior to the release of virion RNA by heat and subsequent nucleic acid amplification by RT-PCR.

RT-PCR enhancement agents. Chemical additives were investigated to overcome RT-PCR inhibition at low virus template levels. Dimethyl sulfoxide (DMSO; 3 and $5 \%$ ), gelatin $(0.2$ and $0.4 \%)$, Tween $20(0.5 \%)$, PEG $4000(2.5,3$, and $5 \%)$, spermidine $(0.10$ and $0.25 \mathrm{mM})$, glycerol (4 and $8 \%)$, single-stranded binding protein $(1$ and $2 \mu \mathrm{l})$, gene 32 protein $(1$ and $2 \mu \mathrm{l})$, and a combination of PEG 4000 and gene 32 protein ( $2 \%$ and $1.5 \mu$ l, respectively) were added to both RT and PCR buffer cocktails before cocktails were dispensed into RT-PCR tubes. The inhibitory effect of oyster extracts was evaluated by serial dilution of concentrated oyster samples and the addition of 2.5 PFU of PV1 prior to the release of virion RNA by heat and subsequent nucleic acid amplification by RT-PCR.

Oligoprobe hybridization. RT-PCR products were diluted in $2 \times$ SSPE (17.53 $\mathrm{g}$ of $\mathrm{NaCl}, 2.76 \mathrm{~g}$ of $\mathrm{NaH}_{2} \mathrm{PO}_{4}, 0.74 \mathrm{~g}$ of EDTA per liter of distilled water) and

\author{
50-GR OYSTER SAMPLE \\ Adsorption-Elution-Ppt'n \\ OYSTER EXTRACT \\ (15-20 ml) \\ 1 \\ FREON EXTRACT TWICE \\ Centrifuge \\ 1 \\ SUPERNATANT \\ 1 \\ PEG PRECIPITATION \\ pH 7.3-7.5 \\ $0.3 \mathrm{M} \mathrm{NaCl}$ \\ 4-6\% PEG \\ $4^{\circ} \mathrm{C}$, overnight \\ Centrifuge \\ 1 \\ PEG RESUSPENSION \\ $50 \mathrm{mM}$ Tris, $0.2 \%$ Tween $20, \mathrm{pH} 9.0$ \\ $(1.5-2.0 \mathrm{ml})$ \\ PRO-CIPITATE ADSORPTION \\ 1:1 Volume ratio \\ Centrifuge \\ $\downarrow$ \\ PRO-CIPITATE ELUTION \\ $50 \mathrm{mM}$ Tris, $0.2 \%$ Tween $20, \mathrm{pH} 9.0$ \\ 1:4 Volume ratio \\ Centrifuge \\ (6-8 ml) \\ PEG PRECIPITATION \\ $\mathrm{pH}$ 7.3-7.5 \\ $0.3 \mathrm{M} \mathrm{NaCl}$ \\ 4-6\% PEG \\ $4^{\circ} \mathrm{C}$, overnight \\ Centrifuge \\ RECONSTITUTE PRECIPITATE \\ $50 \mathrm{mM}$ Tris, $0.2 \%$ Tween $20, \mathrm{pH} 8.0$ \\ $(100-200 \mu \mathrm{l})$ \\ $\downarrow$ \\ RT-PCR and HYBRIDIZATION
}

FIG. 1. Oyster concentration method using Freon extraction, PEG precipitation, and Pro-Cipitate adsorption-elution-precipitation.

blotted on nylon membranes (GeneScreen; DuPont, Boston, Mass.). Alternatively, RT-PCR products were transferred by the method of Southern (22). The DNA was bound by cross-linking with shortwave UV light (Ultraviolet Products, Inc., San Gabriel, Calif.) for 3 to $5 \mathrm{~min}$ at a distance of $15 \mathrm{~cm}$. Protocols for oligoprobe hybridization with cDNA of enteroviruses, HAV, and Norwalk virus have been published previously $(6,7,23)$.

\section{RESULTS}

Development and evaluation of a primary concentration and purification step. Viruses must be concentrated and purified from the complex food matrix to a volume and quality compatible with RT-PCR amplification methods. Starting with virus extracts of oysters by use of an adsorption-elution-precipitation method, the sequential steps of Freon extraction and PEG precipitation were tested for this virus concentration and purification. Fifty-gram oyster samples processed by adsorption-elution-precipitation and seeded with $10^{3}$ to $10^{5} \mathrm{PFU}$ of either PV1 or HAV were extracted twice with Freon to remove 
TABLE 1. Effect of PEG concentration on the recovery of PV1 and HAV by PEG precipitation of oyster extracts

\begin{tabular}{lccc}
\hline \multirow{2}{*}{ Virus } & $\begin{array}{c}\text { \% PEG } \\
(\mathrm{wt} / \mathrm{vol})\end{array}$ & Supernatant & Eluant \\
\cline { 3 - 4 } & 4 & $7 \pm 1$ & $61 \pm 15$ \\
\hline PV1 & 6 & $<1$ & $41 \pm 8$ \\
& 8 & $<1$ & $43 \pm 6$ \\
& 10 & $3 \pm 1$ & $42 \pm 6$ \\
HAV & 4 & $<1$ & $39 \pm 7$ \\
& 6 & $<1$ & $31 \pm 2$ \\
& 8 & $<1$ & $25 \pm 3$ \\
& 10 & $21 \pm 6$ \\
\hline
\end{tabular}

${ }^{a}$ Percent recovery (mean \pm standard deviation) of three replicate samples; total PFU of sample prior to PEG precipitation (about $2 \times 10^{6} \mathrm{PFU}$ of PV1 and $3 \times 10^{5}$ PFU of HAV per 15-g sample) is taken as $100 \%$.

lipids and other toxic components. While a single Freon extraction was effective at removal of extraneous particulates, pigments, and perhaps some of the lipids, a second extraction removed most of the lipid material as evidenced by increased viscosity and turbidity of the solvent phase (data not shown). Virus recoveries after two successive Freon extractions ranged from 61 to $76 \%$ for PV1 and 42 to $53 \%$ for HAV, and results of subsequent experiments indicated that recovery efficiency actually improved at lower titers of both viruses, approaching $100 \%$ at initial input levels of $10^{2}$ PFU (data not shown).

PEG precipitation was used to concentrate viruses in solvent-extracted oyster extracts and reduce sample volume by an average of 10 -fold from 15 to $1.5 \mathrm{ml}$. Viruses were efficiently precipitated with $10 \%$ PEG and $0.3 \mathrm{M} \mathrm{NaCl}$ as evidenced by the absence of viruses in the PEG supernatants (data not shown). Nine different buffer solutions were tested for reconstitution of PEG precipitates. Virus recoveries as assessed by cell culture infectivity were 26 to $51 \%$ for PV1 and 10 to $44 \%$ for HAV (data not shown). While virus recovery varied significantly with shellfish lot for HAV $(P<0.01)$, no statistically significant difference in recovery of PV1 or HAV was found between the different elution buffers when analyzed by nested analysis of variance.

The absence of viruses in PEG supernatants was taken as evidence of efficient virus precipitation but masked infectivity, presumably because of the coprecipitation of shellfish components with viruses. In an effort to improve virus elution from PEG pellets, a number of variables were assessed for their effect on elution efficiency, including PEG concentration for precipitation $(4,6,8,10$, and $12 \%)$, the use of sonication $(1,5$, 10 , and $30 \mathrm{~min}$ ) and detergents (Tween 20 and sodium dodecyl sulfate) during elution of PEG pellets, and the effect of eluant volume (6.7, 3.6, and 2.3 times the original sample volume). The only variable that notably affected virus recovery after elution of PEG pellets was PEG concentration during precipitation. Both PV1 and HAV were effectively precipitated at PEG concentrations as low as $4 \%$, with virus losses to the supernatant of only 7 and $3 \%$, respectively (Table 1). While not quite significant at the $5 \%$ level in statistical analyses, reduction of $\mathrm{PEG}$ concentration to $4 \%$ improved elution recoveries to $62 \%(P=0.05)$ for PV1 and $39 \%(P=0.09)$ for HAV. There was a clear trend toward improved virus elution efficiency for both PV1 and HAV at progressively lower PEG concentrations during precipitation.

To assess the inhibitory effect of oyster components on RTPCR, extracts at various stages of treatment were serially diluted, prepared for RT-PCR, and seeded with 500 PFU of PV1 just prior to reverse transcription reactions. The ability to ob-

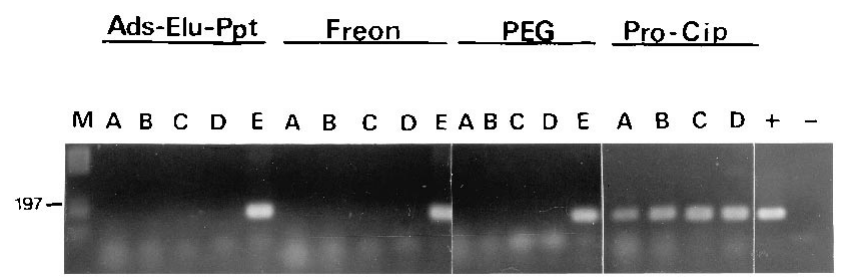

FIG. 2. RT-PCR amplification compatibility of oyster extracts processed by Freon extraction, PEG precipitation, and Pro-Cipitate adsorption-elution-precipitation. Ten-microliter portions of oyster samples after (i) adsorption-elutionprecipitation (Ads-Elu-Ppt), (ii) two Freon extractions (Freon), (iii) PEG precipitation (PEG), and (iv) Pro-Cipitate adsorption-elution-precipitation (ProCip) were diluted serially 10 -fold and supplemented with 500 PFU of PV1. Lanes: A, reactions with $10 \mu \mathrm{l}$ of processed oyster extract; B, C, D, and E, reactions with $10 \mu \mathrm{l}$ of $10^{-0.5}, 10^{-1}, 10^{-2}$, and $10^{-3}$ dilutions of each sample treatment, respectively; + , positive control reaction with no oyster extract added; - , complete reaction cocktail without virus; $\mathrm{M}$, marker.

tain detectable amplicons at the various dilutions by RT-PCR was indicative of the degree of sample inhibition. Specifically, extracts were assayed at the following times: (i) after adsorption-elution-precipitation, (ii) after two Freon extractions, and (iii) after PEG precipitation and subsequent elution. While Freon extraction and PEG precipitation resulted in a 10 -fold overall sample reduction, these treatments did not improve the ability to perform RT-PCR on shellfish extracts (Fig. 2). All samples inhibited RT-PCR at dilutions exceeding $10^{-2}$, i.e., $<0.1 \mu \mathrm{l}$ of shellfish extract in a $100-\mu l$ reaction tube. Because this volume represents $<1 \%$ of the total sample, the sensitivity of RT-PCR detection is greatly reduced. It was hypothesized that shellfish polysaccharides, and specifically glycogen, were the primary cause of the RT-PCR inhibition.

Development and evaluation of a secondary concentration and purification step. The incompatibility of these concentrated shellfish extracts with RT-PCR indicated the need to both further remove inhibitory components and concentrate viruses to yet smaller sample volumes. Pro-Cipitate is a novel acid-alcohol polymer that selectively precipitates proteins while leaving nucleic acids, glycoproteins, and polysaccharides in the resulting supernatant. It was hypothesized that ProCipitate could be used to separate viruses from polysaccharide inhibitors in shellfish extracts by adsorption and subsequent elution from this matrix. Since the efficiency of adsorption and elution of proteins with Pro-Cipitate is dependent upon volume ratios for both precipitation and elution, initial experiments sought to optimize the volumes of Pro-Cipitate and eluant for maximum virus recovery. In these experiments, 0.5 to $1.0-\mathrm{ml}$ volumes of PEG eluant, corresponding to 20 to $25 \mathrm{~g}$ of initial oyster sample, were seeded with $10^{4}$ to $10^{5} \mathrm{PFU}$ of PV1 or HAV, subjected to Pro-Cipitate adsorption and elution conditions, and assayed for virus recovery by cell culture infectivity. Specifically, precipitation efficiency was evaluated at Pro-Cipitate/sample volume ratios of $1: 1,1: 2$, and 1:4, while elution efficiency was evaluated at Pro-Cipitate/eluant volume ratios of 1:4, 1:6, and 1:8. The efficiency of virus adsorption to Pro-Cipitate was significantly different $(P<0.01)$ at various Pro-Cipitate/sample volume ratios, as assessed by the percentage of initial viruses remaining in the supernatant (Table 2). Optimal precipitation occurred at Pro-Cipitate/sample volume ratios of $1: 1$, with $86 \%$ of the PV1 and $100 \%$ of the HAV associated with the Pro-Cipitate solids. After adsorption of viruses at the optimized Pro-Cipitate/PEG eluant volume ratio of 1:1, subsequent elution of viruses from Pro-Cipitate pellets with a $50 \mathrm{mM}$ Tris- $0.2 \%$ Tween 20 (pH 9.0) eluant was effi- 
TABLE 2. Effect of volume ratios of Pro-Cipitate to PEG eluant and Tris eluant to Pro-Cipitate on the efficiency of virus adsorption to and elution from Pro-Cipitate

\begin{tabular}{cccccc}
\hline \multirow{2}{*}{ Virus } & $\begin{array}{c}\text { Pro-Cipitate/ } \\
\text { PEG eluant } \\
\text { vol ratio }\end{array}$ & \multicolumn{2}{c}{$\%$ Recovery $^{a}$ from: } & $\begin{array}{c}\text { Tris-Tween/ } \\
\text { Pro-Cipitate } \\
\text { vol ratio }\end{array}$ & $\begin{array}{c}\% \\
\text { Recovery }^{b} \\
\text { from eluate }^{c}\end{array}$ \\
\hline PV1 & $1: 1$ & $<1$ & $86 \pm 15$ & $1: 4$ & $84 \pm 5$ \\
& $1: 2$ & $<1$ & $106 \pm 28$ & $1: 6$ & $85 \pm 17$ \\
& $1: 4$ & $19 \pm 7^{*}$ & $90 \pm 18$ & $1: 8$ & $71 \pm 3$ \\
HAV & $1: 1$ & $2 \pm 1$ & $116 \pm 28$ & $1: 4$ & $122 \pm 49$ \\
& $1: 2$ & $20 \pm 2^{*}$ & $68 \pm 8$ & $1: 6$ & $83 \pm 6$ \\
& $1: 4$ & $51 \pm 3^{*}$ & $17 \pm 9^{*}$ & $1: 8$ & $75 \pm 10$ \\
\hline
\end{tabular}

${ }^{a}$ Percent recovery (mean \pm standard deviation) of three replicate samples; total PFU of seeded sample prior to Pro-Cipitate adsorption (about $10^{4}$ to $10^{5}$ PFU) is taken as $100 \%$. *, statistically significant $(P<0.01)$ difference.

${ }^{b}$ Percent recovery (mean \pm standard deviation) of three replicate samples; overall recovery based on total PFU of seeded sample prior to Pro-Cipitate adsorption (about $10^{4} \mathrm{PFU}$ ) is taken as $100 \%$. A Pro-Cipitate/PEG eluant volume ratio of $1: 1$ was used during the adsorption step.

${ }^{c}$ The eluate was assayed directly for viruses.

${ }^{d}$ Sup, supernatant. The supernatant was assayed directly for viruses.

${ }^{e}$ Ppt, precipitate. The precipitate was assayed directly for viruses.

cient at all Pro-Cipitate/eluant volume ratios tested, with elution efficiencies of 70 to $100 \%$ for both viruses (Table 2).

The need for large eluant volumes after precipitation of viruses by Pro-Cipitate necessitated an additional concentration step. A second PEG precipitation resulted in a sample of small volume (100 to $200 \mu \mathrm{l})$ that was directly compatible with RT-PCR amplification of viral genomic RNA without further dilution (Fig. 2). On the basis of virus infectivity, both PV1 and HAV were efficiently precipitated at PEG concentrations of $7.5 \%$ or greater, with $<5 \%$ of the input virus remaining in supernatants and averages of 68 and $47 \%$ detected in resuspended precipitates for PV1 and HAV, respectively (data not shown).

Optimization of RT-PCR at low concentration of target viruses. Further evaluation of the Pro-Cipitate adsorption-elution-precipitation method revealed that the efficiency of nucleic acid amplification reactions decreased as virus titers in final PEG precipitates were reduced $\left(<10^{2}\right.$ PFU total), as evidenced by the absence of visible amplification product on agarose gels. It was proposed that the effects of RT-PCR inhibition are compounded when low levels of template nucleic acid are available. A common approach to improving nucleic acid amplification efficiency in complex systems and at low template levels is the addition of PCR enhancement agents (8, 24). To test this approach, oyster samples prepared by solvent extraction, PEG precipitation, and Pro-Cipitate adsorptionelution-precipitation were serially diluted and used for RTPCRs in which reaction cocktails had been modified by the addition of various chemicals. Prior to reverse transcription, each tube was seeded with 2.5 PFU of PV1 and the efficiency of RT-PCR was assessed by the presence of amplicons at each serial dilution. The addition of gelatin $(0.2$ and $0.4 \%)$, DMSO (5\%), Tween $20(0.5 \%)$, spermidine $(0.10$ and $0.25 \mathrm{mM})$, single-stranded binding protein $(1$ and $2 \mu \mathrm{l})$, and gene 32 protein $(1 \mu \mathrm{l})$ had either no effect or a negative effect on the intensity of the RT-PCR signal. Glycerol (4 and 8\%) and DMSO (3\%) improved the intensity of RT-PCR signals, although they did not affect virus detection based on sample dilution (Fig. 3). While the addition of $2 \mu$ l of gene 32 protein slightly improved RT-PCR detection, the greatest effect was seen for PEG 4000 $(2.5 \%)$, which increased virus detection by 1 order of magnitude (Fig. 3). Increasing the PEG 4000 concentration to 3 or

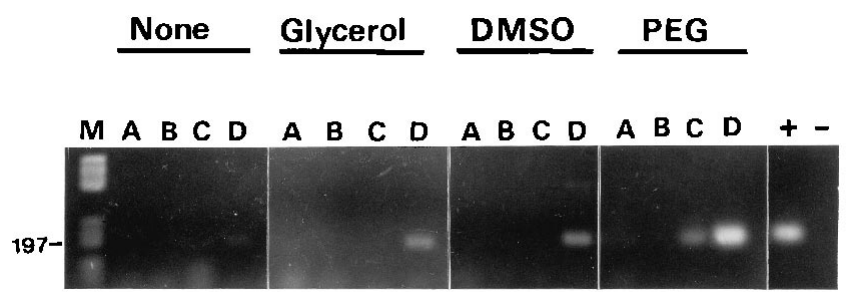

FIG. 3. Effect of RT-PCR enhancement agents on virus detection in oyster concentrates at low template levels. Oyster extracts processed by Freon extraction, PEG precipitation, and Pro-Cipitate adsorption-elution-precipitation were serially diluted and added to unmodified reaction cocktail (None) or those modified by the addition of PEG $(2.5 \%)$, DMSO (3\%), or glycerol $(8 \%)$ and seeded with a constant amount (2.5 PFU) of PV1. Lanes: A, reactions with $10 \mu \mathrm{l}$ of processed oyster extract; $\mathrm{B}, \mathrm{C}$, and $\mathrm{D}$, reactions with $10 \mu \mathrm{l}$ of $10^{-0.5}, 10^{-1}$, and $10^{-2}$ dilutions of each sample treatment, respectively; + , positive control reaction with no oyster extract added; - , complete reaction cocktail without virus; $\mathrm{M}$, marker.

$5 \%$ or the use of a PEG-gene 32 protein combination resulted in a loss of RT-PCR enhancement (data not shown).

Lower limits for virus detection in oyster extracts processed by the developed procedure. Extracts from $50 \mathrm{~g}$ quantities of oyster meat processed by adsorption-elution-precipitation were seeded with about $10^{5}, 10^{4}, 10^{3}, 10^{2}$, and $10^{1}$ PFU of PV1 or HAV and further processed by the successive steps of Freon extraction, PEG precipitation, and Pro-Cipitate adsorptionelution-precipitation. Viruses in final sample concentrates were assayed by both cell culture infectivity and RT-PCR amplification of viral genomic RNA to compare recovery efficiencies and detection limits for the two assay methods. Virus recoveries by cell culture infectivity averaged about $27 \%$ for PV1 and 5\% for HAV and did not vary significantly at different input virus levels (Table 3). There was consistent detection by

TABLE 3. Recovery and detection of PV1 and HAV in oyster extracts concentrated by Freon extraction, PEG precipitation, ProCipitate adsorption-elution, and PEG precipitation

\begin{tabular}{|c|c|c|c|c|c|c|c|}
\hline \multirow[t]{2}{*}{ Virus } & \multirow[t]{2}{*}{$\begin{array}{c}\text { Input } \\
(\mathrm{PFU})^{a}\end{array}$} & \multicolumn{4}{|c|}{$\%$ Recovery $^{b}$} & \multicolumn{2}{|c|}{$\begin{array}{c}\text { No. of } \\
\text { positive } \\
\text { samples/total } \\
\text { no. of } \\
\text { samples }^{c}\end{array}$} \\
\hline & & Freon & PEG & $\begin{array}{l}\text { Pro } \\
\text { eluant }\end{array}$ & $\begin{array}{l}\text { Pro- } \\
\text { PEG }\end{array}$ & $\begin{array}{c}\text { PCR } \\
\text { gel }\end{array}$ & $\begin{array}{c}\text { PCR } \\
\text { hyb }\end{array}$ \\
\hline \multirow[t]{6}{*}{ PV1 } & $1 \times 10^{5}$ & 89 & 47 & 52 & 35 & $3 / 3$ & $3 / 3$ \\
\hline & $1 \times 10^{4}$ & 107 & 59 & 70 & 44 & $3 / 3$ & $3 / 3$ \\
\hline & $2 \times 10^{3}$ & 83 & 42 & 35 & 25 & $3 / 3$ & $3 / 3$ \\
\hline & 120 & $\mathrm{ND}^{d}$ & ND & ND & 23 & $3 / 3$ & $3 / 3$ \\
\hline & 10 & ND & ND & ND & 23 & $0 / 3$ & $2 / 3$ \\
\hline & 7 & ND & ND & ND & 14 & $0 / 3$ & $1 / 3$ \\
\hline \multirow[t]{6}{*}{ HAV } & $2 \times 10^{5}$ & 33 & 11 & 16 & 4 & $3 / 3$ & $3 / 3$ \\
\hline & $2 \times 10^{4}$ & 39 & 20 & 44 & 11 & $3 / 3$ & $3 / 3$ \\
\hline & $5 \times 10^{2}$ & 98 & 8 & 13 & 9 & $3 / 3$ & $3 / 3$ \\
\hline & $2 \times 10^{2}$ & ND & ND & ND & 1 & $3 / 3$ & $3 / 3$ \\
\hline & 36 & ND & ND & ND & $<2$ & $0 / 3$ & $0 / 3$ \\
\hline & 24 & ND & ND & ND & 4 & $0 / 3$ & $1 / 3$ \\
\hline
\end{tabular}

${ }^{a}$ Recovery based on initial virus input before Freon extraction of oyster extract from 50-g samples; total PFU of sample prior to Freon extraction is taken as $100 \%$ at input levels of $>10^{2}$; at input levels of $<10^{2}$, total PFU of sample estimated from infectivity titer of stock virus.

${ }^{b}$ Mean percent recovery of three replicate samples. Extracts were concentrated by Freon extraction (Freon), PEG precipitation (PEG), Pro-Cipitate adsorption-elution (Pro eluant), and Pro-Cipitate-PEG precipitation (Pro-PEG).

c Detection was done by agarose gel electrophoresis of PCR product (PCR gel) and then by oligonucleotide probe hybridization of PCR product (PCR hyb).

${ }^{d} \mathrm{ND}$, no data; titer too low to detect until final concentration and purification. 
A
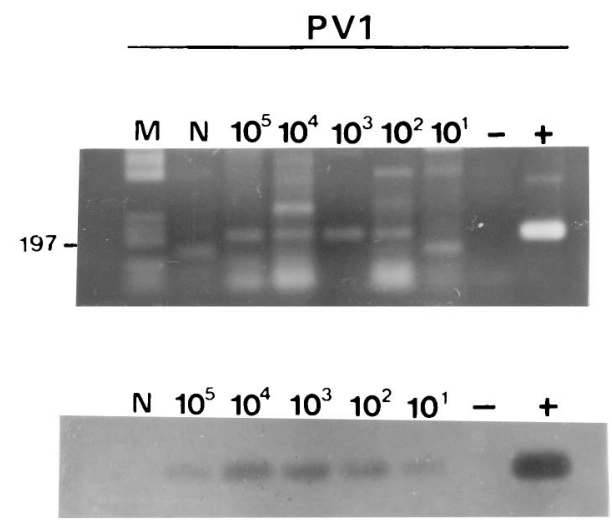

B

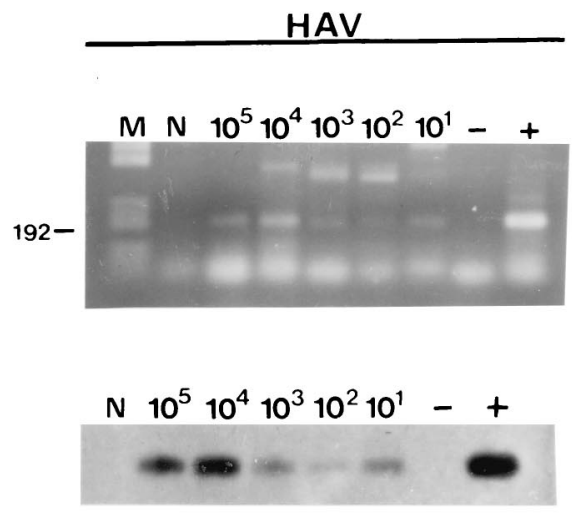

FIG. 4. RT-PCR detection of PV1 and HAV in artificially contaminated oyster extracts. Fifty-gram oyster samples processed by adsorption-elution-precipitation were inoculated with $10^{5}, 10^{4}, 10^{3}, 10^{2}$, and $10^{1}$ PFU of PV1 or HAV and concentrated for virus recovery by Freon extraction, PEG precipitation, and Pro-Cipitate adsorption-elution-precipitation. One-tenth of the sample concentrate volume was subjected to RT-PCR amplification. PV1 (A) and HAV (B) amplification reactions were performed on agarose gels and confirmed by Southern transfer and internal oligoprobe hybridization. The corresponding initial inoculum level in untreated oyster extracts is given above each lane. Lanes: M, marker; N, uninoculated oyster extract concentrated by Freon extraction, PEG precipitation, and Pro-Cipitate adsorption-elution-precipitation; +, positive control reaction for amplification with no extract added; - , complete reaction cocktail without virus.

RT-PCR amplification in samples with initial inoculum levels of $10^{2}$ PFU or greater for both viruses (Fig. 4). At input levels of $10^{1}$ PFU of test viruses, RT-PCR amplification bands confirmed by oligoprobe hybridization were obtained for $50 \%$ of the samples inoculated with PV1 and $15 \%$ of the samples inoculated with HAV. At low (<100-PFU) input levels of viruses, $50 \%$ of the sample was analyzed by each of the two detection methods, implying that RT-PCR detection may be twice as sensitive as reported here if applied to the entire available sample concentrate obtained from processing a $50 \mathrm{-g}$ oyster sample.

To assess the efficiency of the developed method for Norwalk virus detection, 50-g oyster samples processed by adsorption-elution-precipitation were seeded with 450-, 45-, and 4.5- $\mu$ l volumes of a Norwalk virus fecal extract and processed by the successive steps of Freon extraction, PEG precipitation and elution, and Pro-Cipitate adsorption-elution-precipitation. On the basis of previous studies, these inoculum volumes contained $4.5 \times 10^{4}, 4.5 \times 10^{3}$, and 450 amplifiable genomic units of Norwalk virus, respectively, which corresponds approximately to the number of virions (6). Final sample concentrates were serially diluted and subjected to RT-PCR amplification of viral genomic RNA. Amplified Norwalk virus cDNA was detected in samples containing $\geq 4.5 \times 10^{3}$ amplifiable genomic units of Norwalk virus (Fig. 5). Because only $1 / 10$ of the concentrate volume was subjected to RT-PCR and oligoprobe analysis, and because detection was possible at a 10-fold dilution, Norwalk virus detection may be as much as 100 -fold more sensitive than the level of Norwalk virus seeded in these samples.

To assess the efficiency of the combined extraction procedure in virus recovery from whole oysters, 50-g quantities of oyster meat were seeded with $10^{5}, 10^{4}$, or $10^{3}$ PFU of PV1 or HAV or $10^{5}$ RT-PCR-amplifiable units of Norwalk virus and processed for virus concentration by adsorption-elution-precipitation followed by the successive steps of Freon extraction, PEG precipitation, and Pro-Cipitate adsorption-elution-precipitation. Final sample concentrates were serially diluted and subjected to RT-PCR amplification of viral genomic RNA. In all samples, there was consistent detection by RT-PCR ampli- fication as confirmed by internal oligoprobe hybridization of ethidium bromide-stained agarose gels (Fig. 6).

\section{DISCUSSION}

The development of nucleic acid amplification methods to detect viral contamination in shellfish is complicated by the following three factors: (i) shellfish concentrates are usually large in volume (10 to $50 \mathrm{ml}$ ), (ii) they have low viral titers, and (iii) they contain compounds that interfere with enzymatic nucleic acid amplification reactions. Several virus concentra-
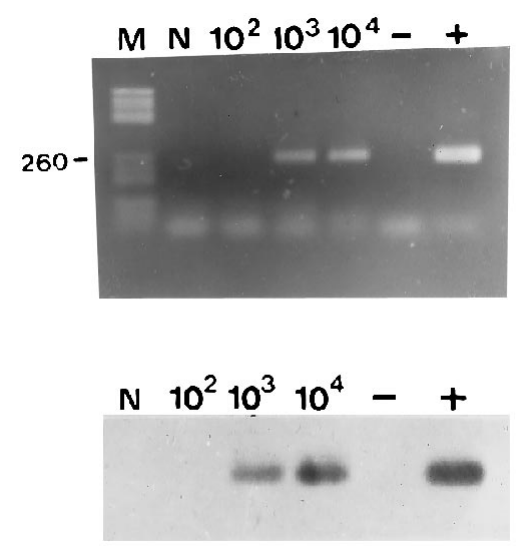

FIG. 5. RT-PCR detection of Norwalk virus in artificially contaminated oyster extracts. Fifty-gram oyster samples processed by adsorption-elution-precipitation were inoculated with $10^{4}, 10^{3}$, and $10^{2}$ RT-PCR-amplifiable units of Norwalk virus and concentrated for virus recovery by Freon extraction, PEG precipitation, and Pro-Cipitate adsorption-elution-precipitation. One-tenth of the sample concentrate volume was subjected to RT-PCR amplification. Norwalk virus amplification reactions on agarose gels were confirmed by Southern transfer and internal oligoprobe hybridization. The corresponding initial inoculum level in untreated oyster extracts is given above each lane. Lanes: M, marker; $\mathrm{N}$, uninoculated oyster extract concentrated by Freon extraction, PEG precipitation, and Pro-Cipitate adsorption-elution-precipitation; +, positive control reaction for amplification with no extract added; -, complete reaction cocktail without virus. 
A
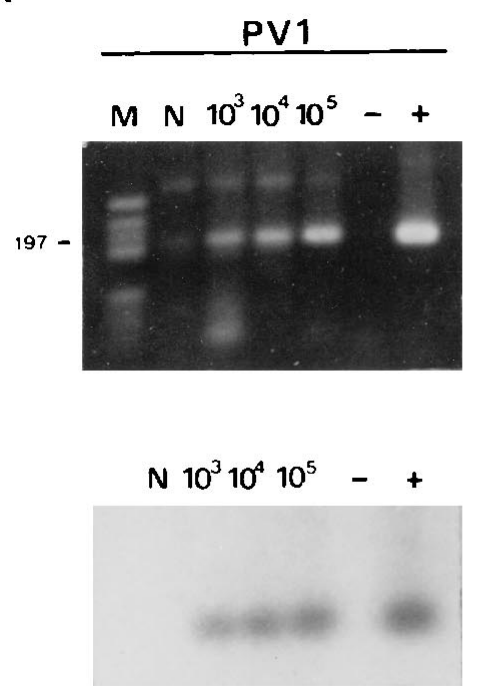

B
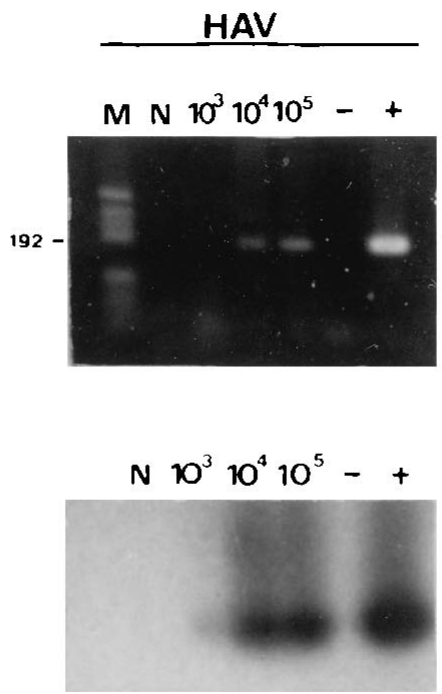

C
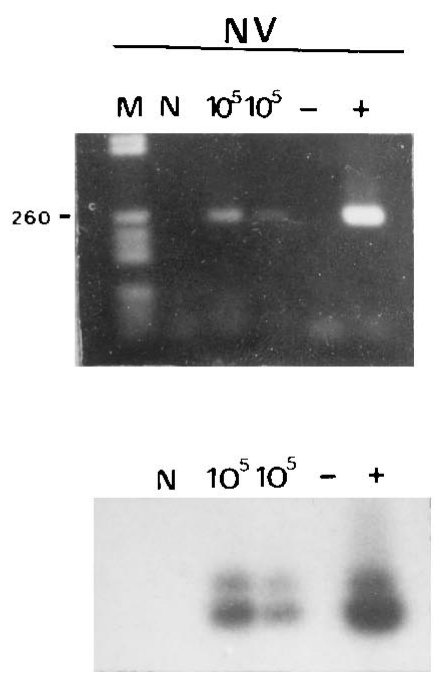

FIG. 6. RT-PCR detection of PV1, HAV, and Norwalk virus in artificially contaminated oysters. Fifty-gram oyster samples were inoculated with $10^{5}, 10^{4}$, and $10^{3}$ PFU of PV1 or HAV or $10^{5}$ RT-PCR-amplifiable units of Norwalk virus and processed for virus concentration by adsorption-elution-precipitation followed by the successive steps of Freon extraction, PEG precipitation, and Pro-Cipitate adsorption-elution-precipitation. One-tenth of the sample concentrate volume was subjected to RT-PCR amplification. PV1 (A), HAV (B), and Norwalk virus (C) amplification reactions were done on agarose gels and confirmed by Southern transfer and internal oligoprobe hybridization. The corresponding initial inoculum level in oyster samples is given above each lane. Lanes: M, marker; N, uninoculated oyster sample concentrated by adsorption-elution-precipitation, Freon extraction, PEG precipitation, and Pro-Cipitate adsorption-elution-precipitation; + , positive control reaction for amplification with no extract added; -, complete reaction cocktail without virus.

tion and purification methods were investigated to overcome these problems and achieve RT-PCR amplification of viruses in oysters. The three key concentration and purification methods evaluated in this study were Freon extraction, PEG precipitation, and Pro-Cipitate adsorption-elution-precipitation.

Freon extraction and PEG precipitation were employed sequentially as purification and concentration steps for viruses in 50 -g oyster samples processed initially by adsorption-elutionprecipitation. Consistent with the results of other investigators (27), Freon extraction effectively removed lipids and other contaminants from oyster extracts with small losses of virus. PEG, a nontoxic, water-soluble fractional precipitating agent, efficiently precipitated $>99 \%$ of both the PV1 and the HAV at concentrations of 6 to $10 \%$. This is also consistent with the findings of other investigators who reported 6 to $8 \%$ PEG as optimal for precipitation of HAV, rotavirus Wa, and Norwalk virus from shellfish homogenates at various stages of virus concentration $(17,29)$.

The recovery of viruses by elution from PEG pellets was not efficient in this study. Zhou et al. (29) have suggested that virus aggregation may be responsible for virus loss during elution of PEG precipitates. Alternatively, virus adsorption to coprecipitated proteins may mask infectivity and/or hinder virion elution from PEG pellets. While some investigators have reported improved recoveries by sonication, shaking, and increased eluant volumes, none of these treatments was effective in this study. Reduction of PEG concentration was the only variable that significantly improved virus recovery upon elution of PEG precipitates. The most likely explanation for this phenomenon is that the lower PEG concentration decreases coprecipitation of other proteins, which may reduce the tendency of viruses to aggregate, adsorb, or otherwise bind to these precipitated materials.

While Freon extraction, PEG precipitation, and elution resulted in a 10 -fold overall sample volume reduction, this con- centration step did not sufficiently remove inhibitors of the RT-PCRs. Hill et al. (11) reported similar interferences when extracting nucleic acids from shellfish meats for nucleic acid amplification of bacterial DNA sequences and proposed that glycogen was the major cause of this interference. In an effort to selectively separate viruses from contaminating polysaccharides, we applied Pro-Cipitate and PEG in a secondary concentration and purification step. Pro-Cipitate selectively separated proteins (including viruses) from other RT-PCR inhibitors when applied in an adsorption-elution-precipitation protocol. Viruses in PEG eluants were effectively precipitated with 98 to $99 \%$ efficiency at Pro-Cipitate/sample ratios of $1: 1$, and recovery of virus infectivity after elution approached 70 to $100 \%$. A second step of PEG precipitation proved to be an effective reconcentration method that produced RT-PCR-compatible final concentrates that were small in volume $(100$ to $150 \mu \mathrm{l})$.

Because the efficiency of RT-PCR amplification of viral nucleic acid sequences decreased at low levels of viruses, it was suspected that the effect of residual RT-PCR inhibitors is greater at low copy numbers. Several RT-PCR buffer additives were evaluated in an effort to reverse this inhibition. These additives are used widely in overcoming PCR inhibition due to interfering materials in plant DNA extracts $(5,8,18,24)$. While DMSO and glycerol improved the intensity of RT-PCR bands, only PEG 4000 produced a quantifiable improvement in end point titer detection at low template levels, although amplicon bands remained faint. Because Demeke and Adams (8) previously reported that PEG 4000 overcame the PCR inhibitory effects of acidic polysaccharides in DNA extracts from plant tissues, we propose that the RT-PCR inhibition of oyster extract may also be due to acidic polysaccharides and not glycogen, as previously proposed (11).

There is concern regarding the relationship between RTPCR detection of viral nucleic acid sequences and the presence 
of infectious virus in environmental samples (16). Isolation of intact virions from shellfish extracts, as developed in this study, rather than the alternative approach of extraction of total sample RNA, enables direct comparison of detection by nucleic acid amplification and cell culture infectivity assay without further manipulation of the nucleic acids. This study shows good correlation between detection by viral infectivity and RT-PCR amplification and oligoprobe hybridization for HAV and PV1 in final shellfish concentrates.

The developed procedure is a rapid means of concentrating and purifying enteric virus particles in oyster extracts for RTPCR amplification and oligoprobe detection. The final concentrate is small in volume (100 to $200 \mu \mathrm{l})$ and clean enough for amplification of enteric virus nucleic acid by direct RT-PCR. Because visible detection of RT-PCR product on ethidium bromide-stained, electrophoresed agarose gels decreased with decreasing copy number, oligoprobe hybridization of RT-PCR product was essential for both detection and confirmation of viral genomic amplicons. Nonspecific cDNA amplification was detectable on electrophoresed agarose gels for most samples and increased with decreasing copy number. Virus recoveries were about $30 \%$ for poliovirus and about $5 \%$ for HAV. Detection limits were $10^{1}$ to $10^{2} \mathrm{PFU} / 50$-g oyster extract. At a level of about $10^{1}$ PFU, RT-PCR detection of viral contamination was possible in $50 \%$ of the samples inoculated with PV1 and $15 \%$ of the samples inoculated with HAV. On the basis of virus recoveries demonstrated by cell culture infectivity, the RT-PCR method was able to detect as little as 1 PFU of target viruses per $10 \mu \mathrm{l}$ of final concentrate, corresponding to about $5 \mathrm{~g}$ of original oyster meat. The method was capable of recovering Norwalk virus with a similar estimated limit of detection. Since only 10 to $30 \%$ of the final concentrate was used in RT-PCR amplifications, the procedure may be more sensitive by up to 1 order of magnitude. Additional refinements of the method such as hot starts for RT-PCR (4) and the application of a quantitative approach to nucleic acid amplification (19, 28) may result in the elimination of nonspecific amplification and further improvements in the detection limits of the method.

\section{ACKNOWLEDGMENTS}

This work was partially supported by funds from the National Shellfish Indicator Study (NOAA award NA17FQ0551-01 and contract NIS-91-2). The research described in this article was partially funded by the U.S. Environmental Protection Agency through Assistance Agreement R817153.

\section{REFERENCES}

1. Atmar, R. L., T. G. Metcalf, F. H. Neill, and M. K. Estes. 1991. Detection of human viruses in oysters using the polymerase chain reaction. Appl. Environ. Microbiol. 59:631-635.

2. Chapman, N. M., S. Tracey, C. J. Gauntt, and U. Fortmueller. 1990. Molecular detection and identification of enteroviruses using enzymatic amplification and nucleic acid hybridization. J. Clin. Microbiol. 28:843-850.

3. Cromeans, T., M. D. Sobsey, and H. A. Fields. 1987. Development of a plaque assay for a cytopathic, rapidly replicating isolate of hepatitis A. J. Med. Virol. 22:45-56.

4. D'Aqula, R. T., L. J. Bechtel, J. A. Videler, J. J. Eron, P. Gorczyca, and J. C. Kaplan. 1991. Maximizing sensitivity and specificity of PCR by pre-amplification heating. Nucleic Acids Res. 19:3749.
5. DeCesare, J. 1992. Personal communication.

6. De Leon, R., S. M. Matsui, R. S. Baric, J. E. Herrmann, N. R. Blacklow, H. B. Greenberg, and M. D. Sobsey. 1992. Detection of Norwalk virus in stool specimens by reverse transcriptase-polymerase chain reaction and nonradioactive oligoprobes. J. Clin. Microbiol. 30:3151-3157.

7. De Leon, R., C. Shieh, R. S. Baric, and M. D. Sobsey. 1990. Detection of enteroviruses and hepatitis A virus in environmental samples by gene probes and polymerase chain reaction, p. 833-853. In Proceedings of the 1989 Water Quality and Technology Conference. American Water Works Association, Denver, Colo.

8. Demeke, T., and R. P. Adams. 1992. The effects of plant polysaccharides and buffer additives on PCR. BioTechniques 12:332-333.

9. Gerba, C. P. 1988. Viral disease transmission by seafoods. Food Technol. 42:99-103.

10. Gouvea, V., R. I. Glass, P. Ward, K. Taniguchi, H. F. Clark, B. Forrester, and Z. Y. Fang. 1990. Polymerase chain reaction amplification and typing of rotavirus nucleic acid from stool specimens. J. Clin. Microbiol. 28:276-282.

11. Hill, W. E., S. P. Keasler, M. W. Truckess, P. Feng, C. A. Kaysner, and K. A. Lampel. 1991. Polymerase chain reaction identification of Vibrio vulnificus in artificially contaminated oysters. Appl. Environ. Microbiol. 57:707-711.

12. Hyypia, T., P. Auvinen, and M. Maaronen. 1989. Polymerase chain reaction of human picornaviruses. J. Gen. Virol. 70:3261-3268.

13. Jansen, R. W., G. Siegl, and S. M. Lemon. 1990. Molecular epidemiology of human hepatitis A virus defined by antigen-capture polymerase chain reaction method. Proc. Natl. Acad. Sci. USA 87:2867-2871.

14. Jaykus, L. A., M. T. Hemard, and M. D. Sobsey. 1994. Human enteric pathogenic viruses, p. 92-153. In C. R. Hackney and M. D. Pierson (ed.), Environmental indicators and shellfish safety. Chapman and Hall, New York.

15. Keating, M. H. 1985. M.S. thesis. University of North Carolina, Chapel Hill

16. Kopecka, H. S., S. Dubrou, J. Prevot, J. Marechal, and J. M. Lopez-Pila. 1993. Detection of naturally occurring enteroviruses in waters by reverse transcription, polymerase chain reaction, and hybridization. Appl. Environ. Microbiol. 59:1213-1219.

17. Lewis, G. D., and T. G. Metcalf. 1988. Polyethylene glycol precipitation for recovery of pathogenic viruses, including hepatitis A virus and human rotavirus, from oyster, water, and sediment samples. Appl. Environ. Microbiol. 54:1983-1988

18. Oshima, R. G. 1992. Single-stranded DNA binding protein facilitates amplification of genomic sequences by PCR. BioTechniques 13:188.

19. Piatak, M., K. C. Luk, B. Williams, and J. D. Lifson. 1993. Quantitative competitive polymerase chain reaction for accurate quantitation of HIV DNA and RNA species. Biotechniques 14:70-80.

20. Richards, G. P. 1985. Outbreaks of shellfish-associated enteric virus illness in the United States: requisite for development of viral guidelines. J. Food Prot. 48:815-823.

21. Rotbart, H. A. 1990. Enzymatic amplification of the enteroviruses. J. Clin. Microbiol. 28:438-442.

22. Sambrook, J., E. F. Fritsch, and T. Maniatis. 1989. Molecular cloning: a laboratory manual. Cold Spring Harbor Laboratory Press, Cold Spring Harbor, N.Y.

23. Schwab, K. J., R. De Leon, R. S. Baric, and M. D. Sobsey. 1991. Detection of rotaviruses, enteroviruses, and hepatitis A virus by reverse transcriptasepolymerase chain reaction, p. 475-491. In Proceedings of the 1990 Water Quality and Technology Conference. American Water Works Association, Denver, Colo

24. Schwartz, K., T. Hansen-Gagge, and C. Bertram. 1990. Improved yields of long PCR products using gene 32 protein. Nucleic Acids Res. 18:1079.

25. Sobsey, M. D. 1987. Methods for recovering viruses from shellfish, seawater, and sediments, p. 77-108. In G. Berg (ed.), Methods for recovering viruses from the environment. CRC Press, Inc., Boca Raton, Fla.

26. Sobsey, M. D., R. J. Carrick, and H. R. Jensen. 1978. Improved methods for detecting enteric viruses in oysters. Appl. Environ. Microbiol. 36:121-130.

27. Sullivan, R., J. T. Peeler, J. T. Tierney, and E. P. Larkin. 1984. Evaluation of a method for recovering poliovirus 1 from 100-gram oyster samples. J. Food Prot. 47:108-110.

28. Sykes, P. J., S. H. Neoh, M. J. Brisco, E. Huches, J. Condon, and A. A. Morley. 1992. Quantitation of targets for PCR by use of limiting dilution. BioTechniques 13:444-449.

29. Zhou, Y. J., M. K. Estes, X. Jaing, and T. G. Metcalf. 1991. Concentration and detection of hepatitis A virus and rotavirus from shellfish by hybridization tests. Appl. Environ. Microbiol. 57:2963-2968. 